\title{
A Note on the Relationship between the Pearson Product-Moment and the Spearman Rank-Based Coefficients of Correlation
}

\section{Todd Christopher Headrick}

Department of CQMSE (Quantitative Methods-Statistics), Southern Illinois University, Carbondale, USA

Email:headrick@siu.edu

How to cite this paper: Headrick, T.C. (2016) A Note on the Relationship between the Pearson Product-Moment and the Spearman Rank-Based Coefficients of Correlation. Open Journal of Statistics, 6, 1025 1027.

http://dx.doi.org/10.4236/ojs.2016.66082

Received: September 15, 2016

Accepted: November 14, 2016

Published: November 17, 2016

Copyright $\odot 2016$ by author and Scientific Research Publishing Inc. This work is licensed under the Creative Commons Attribution International License (CC BY 4.0)

http://creativecommons.org/licenses/by/4.0/

\begin{abstract}
This note derives the relationship between the Pearson product-moment coefficient of correlation and the Spearman rank-based coefficient of correlation for the bivariate normal distribution. This new derivation shows the relationship between the two correlation coefficients through an infinite cosine series. A computationally efficient algorithm is also provided to estimate the relationship between the Pearson product-moment coefficient of correlation and the Spearman rank-based coefficient of correlation. The algorithm can be implemented with relative ease using current modern mathematical or statistical software programming languages e.g. R, SAS, Mathematica, Fortran, et al. The algorithm is also available from the author of this article.
\end{abstract}

\section{Keywords}

Bivariate Normal Distribution, Product-Moment Correlation, Rank-Based Correlation, Gibbs Phenomenon

\section{Introduction}

The Pearson product-moment coefficient of correlation can be interpreted as the cosine of the angle between variable vectors in $n$ dimensional space (e.g. [1] and [[2], p. 702]). Pearson [3] showed that the relationship of turning Spearman rank-based correlation coefficients $\left(\rho_{S}\right)$ for the bivariate normal distribution into Pearson product-moment correlations $(\rho)$, which was contrived based on the so-called correlation of grades, for large samples to be:

$$
\rho_{S}=(6 / \pi) \sin ^{-1}((1 / 2) \rho) \text {. }
$$


For finite (small) samples, Moran [4] derived the relationship between the Pearson and Spearman coefficients of correlation for the bivariate normal distribution, which also appears in Headrick [[5] p. 114], to be:

$$
\rho_{S}=(6 / \pi)\left\{((n-2) /(n+1)) \sin ^{-1}((1 / 2) \rho)+(1 /(n+1)) \sin ^{-1}(\rho)\right\} .
$$

Taking the limit as $n \rightarrow \infty$ in Equation (2) will reduce Equation (2) to Equation (1). We would also note that Höffding [6] demonstrated that the Spearman rank correlation tends to normality for any given parent population.

\section{Mathematical Development}

In view of the above, this note derives the relationship between the Pearson product-moment correlation coefficient and the Spearman rank-based correlation coefficient for the bivariate normal distribution, in a different manner from either the Pearson [3] or the Moran [4] derivations, through the following infinite cosine series:

$$
\sum_{n=1}^{\infty} \cos (n x) / n \text {. }
$$

Specifically, if we let $z=\cos (x)+i \sin (x)$, then

$$
\sum_{n=1}^{m} y^{n-1} z^{n}=\left(z\left\{1-(y z)^{m}\right\}\right) /(1-y z)
$$

where it follows that for $|y|<1$, that

$$
\begin{aligned}
& \sum_{n=1}^{\infty} y^{n-1}(\cos (n x)+i \sin (n x)) \\
& =(\cos (x)+i \sin (x)) /(1-y \cos (x)-y i \sin (x)) \\
& =((\cos (x)-y)+i \sin (x)) /\left(1-2 y \cos (x)+y^{2}\right) .
\end{aligned}
$$

Thus, from Equation (5) we have:

$$
\sum_{n=1}^{\infty} y^{n-1} \cos (n x)=(\cos (x)-y) /\left(1-2 y \cos (x)+y^{2}\right) .
$$

The series associated with Equation (6) is uniformly convergent for all values of $y$ and for $|y| \leq p<1$. As such, integrating with respect to $y$, where $0<y<1$ yields:

$$
\begin{aligned}
\sum_{n=1}^{\infty} y^{n}(\cos (n x)) / n & =\int_{0}^{y}\left((\cos (x)-t) /\left(1-2 t \cos (x)+t^{2}\right)\right) \mathrm{d} t \\
& =(-1 / 2)\left(\ln \left(1-2 y \cos (x)+y^{2}\right)\right) .
\end{aligned}
$$

Let $x$ neither be zero nor a multiple of $2 \pi$. As such, it necessarily follows that the series in Equation (3) is convergent. Hence, for $0 \leq y \leq 1 ; y^{n}$ is positive, monotonic, decreasing, and bounded. Whence, the series

$$
\sum_{n=1}^{\infty} y^{n} \cos (n x) / n
$$

is, therefore, uniformly convergent for $0 \leq x \leq 1$. Subsequently letting $y \rightarrow 1$, noting again that $x$ is neither zero nor a multiple of $2 \pi$, it follows that Equation (3) can be expressed as

$$
\sum_{n=1}^{\infty} \cos (n x) / n=(-1 / 2) \ln (2-2 \cos (x))=-\ln (2 \sin ((1 / 2) x)) .
$$




\section{Main Result and Conclusions}

Setting $x=(\pi / 3) \rho_{S}$ in Equation (9), and through subsequent inverse exponentiation (1/e) of Equation (9), yields the relationship (for large samples) between the Pearson product-moment correlation and the Spearman rank-based correlation coefficients as

$$
\rho=2 \sin \left((\pi / 6) \rho_{S}\right)
$$

for the bivariate normal distribution. In conclusion, the algorithm provided below in Equation (11), which has an oscillating effect of the Gibbs phenomenon [7], to demonstrate the analytical derivation above is given as:

$$
\hat{\rho}=\left(1-(1 / k) \sum_{n=1}^{k} \cos \left(n(\pi / 3) \rho_{S}\right) / n\right)^{k}
$$

where $0 \leq\left|\rho_{S}\right| \leq 1, k$ is finite, and where Equation (11) converges to Equation (10) as $k \rightarrow \infty$. Finally, in terms of the error associated with Equation (11), it is straight-forward to see through real analysis, that $\rho_{S}$ and $\rho$ have a maximum absolute deviation when $\rho_{S}=0.566467 \cdots$ and hence Equation (10) would result in $\rho=0.584543 \cdots$. As such, at this maximum point of deviation, given that $k=10000$ in Equation (11), that the absolute error is less than $5.42 \times 10^{-5}$ when juxtaposed with Equation (10).

\section{References}

[1] Rodgers, J.L. and Nicewander, W.A. (1988) Thirteen Ways to Look at the Correlation Coefficient. The American Statistician, 42, 59-66. https:/doi.org/10.2307/2685263

[2] Stein, S.K. and Barcellos, A. (1992) Calculus and Analytic Geometry. 5th Edition, McGraw-Hill, Inc., New York.

[3] Pearson, K. (1907) Mathematical Contributions to the Theory of Evolution. XVI. On Further Methods of Determining Correlation. Drapers Company of Research Memoirs, Biometric Series, Cambridge University Press, Cambridge.

[4] Moran, P.A.P. (1948) Rank Correlation and Product-Moment Correlation. Biometrika, 35, 203-206. https:/doi.org/10.1093/biomet/35.1-2.203

[5] Headrick, T.C. (2010) Statistical Simulation: Power Method Polynomials and Other Transformations. Chapman \& Hall/CRC, Boca Raton.

[6] Höffding, W. (1948) A Class of Statistics with Asymptotically Normal Distributions. The Annals of Mathematical Statistics, 19, 293-325. https:/doi.org/10.1214/aoms/1177730196

[7] Gibbs, J.W. (1899) Fourier Series. Nature, 59, 200, 606. 
Submit or recommend next manuscript to SCIRP and we will provide best service for you:

Accepting pre-submission inquiries through Email, Facebook, LinkedIn, Twitter, etc. A wide selection of journals (inclusive of 9 subjects, more than 200 journals)

Providing 24-hour high-quality service

User-friendly online submission system

Fair and swift peer-review system

Efficient typesetting and proofreading procedure

Display of the result of downloads and visits, as well as the number of cited articles

Maximum dissemination of your research work

Submit your manuscript at: http://papersubmission.scirp.org/

Or contact ojs@scirp.org 